\title{
Aula de Matemática: as relações entre o rujeito e o conhecimento matemático
}

\section{Math Class: the relationship between subject and mathematical knowledge}

Carla Cristina Pompeu*

\begin{abstract}
Resumo
Este artigo apresenta uma breve discussão sobre alguns estudos que discorrem sobre a relação do sujeito com o conhecimento matemático - escolar ou não - e examinam de que modo se dá a relação do sujeito com tal conhecimento no interior do ambiente escolar. O objetivo é discutir, a partir de diferentes referenciais teóricos sobre aprendizagem e aprendizagem situada, a relação do sujeito com o conhecimento matemático em situações distintas de aprendizagem, levando em conta os modos com os quais os sujeitos aprendem e conhecem na escola, bem como a importância, para o processo escolar, de conhecimentos oriundos de experiências externas à escola.
\end{abstract}

Palavras-chave: Educação Matemática. Prática Social. Relação com o Saber Matemático. Aprendizagem Situada.

\begin{abstract}
This paper presents a brief discussion about some studies regarding the relation of the subject with mathematical knowledge - academic or not - and examine how that relationship between the subject with such knowledge occurs inside the school environment. The goal is to discuss from different theoretical references on learning and situated learning the relation of the subject with mathematical knowledge in different learning situations, taking into account the ways in which individuals learn and know

\footnotetext{
" Mestre em Ensino de Ciências e Matemática pela Universidade de São Paulo (USP). Professora Assistente da Universidade Federal do Triângulo Mineiro (UFTM), Uberaba, MG, Brasil. Endereço para correspondência: Rua João Mendes, 25, Bairro Brigadeiro Faria Lima, CEP: 13345-456, Indaiatuba, SP, Brasil. E-mail: ccpompeu@gmail.com
} 
the school, as well as the importance, for the school process, of knowledge that comes from experiences outside the school.

Keywords: Mathematics Education. Social Practice. Relationship with the Mathematical Knowledge. Situated Learning.

\section{A matemática como prática social}

O processo de ensino e aprendizagem e o modo como ele se configura a partir das relações entre sujeito e saber estão entre as questões que têm motivado pesquisadores da área da educação, dando margem a novos estudos. A relevância do conhecimento cotidiano no interior do processo escolar tornouse tema de pesquisas recentes em educação matemática, uma vez que a escola configura-se como um lugar de interação e troca de conhecimentos oriundos de outras experiências de aprendizagem. Afinal, o sujeito que aprende e que está inserido em diferentes ambientes de aprendizagem é um sujeito social que se constitui, segundo Charlot (2001), como um sujeito único, um ser singular com história própria que interpreta e fornece sentidos ao mundo, à posição que nele ocupa e às suas relações com outros sujeitos.

Dessa forma, não se pode falar em um sujeito desvinculado do social, pois, ainda de acordo com Charlot (2001), o sujeito é ativo e age no e sobre o mundo; ele se forma e modifica o ambiente e as pessoas com quem interage por meio das relações sociais em que se envolve. Uma vez considerado como ser social, suas experiências de aprendizagem misturam-se em momentos de aprender únicos, porém com sentidos próprios designados pelo modo de conhecer de cada sujeito.

Ao longo deste artigo, o termo experiência refere-se à definição de Dewey (1974). Através das contribuições de Willian James, Dewey discute sobre o significado desse termo:

Experiência é o que James chamou de uma palavra de duplo sentido. Como suas congêneres, vida e história, ela inclui aquilo que eles se esforçam por conseguir, amam, crêem e suportam, e também como os homens agem e sofrem a ação, as maneiras pelas quais eles realizam e padecem, desejam e desfrutam, vêem e crêem, imaginam - em suma, processos de experienciar [...]. Ela é de "duplo sentido" nisto, em que, em sua integridade primitiva, não admite divisão entre ato e matéria, sujeito e objeto, mas os contém numa totalidade não analisada. "Coisa"e "pensamento", como diz James no 
mesmo contexto, são de sentido único; referem-se a produtos discriminados pela reflexão a partir da experiência primária" (DEWEY, 1974, p. 168).

O sujeito social e suas experiências oriundas de práticas de aprendizagens diversas tornam toda relação com o saber repleta de sentidos e significados únicos, destacando a necessidade de um olhar singular para momentos de aprendizagens específicos, como o momento de aprendizagem escolar. Em contrapartida, o cenário educacional brasileiro configura-se pela dicotomia entre matemática escolar e matemática do cotidiano.

Documentos oficiais sobre educação defendem a necessidade de contextualização e a relevância do conhecimento matemático cotidiano no ambiente escolar. Monteiro e Nacarato (2005) discutem sobre as possibilidades de relação entre a matemática do cotidiano e a escolar, apresentadas nos Parâmetros Curriculares Nacionais, e defendem:

[...] a relação entre conhecimento matemático escolar e conhecimento matemático cotidiano tende a se limitar a uma visão psicológica em que o conhecimento cotidiano assume um papel de coadjuvante, ou seja, é assumido como um ponto de partida a ser superado num processo de sobreposição pelo conhecimento escolar. Entretanto, nesse mesmo documento, encontramos indicações contraditórias sobre o entendimento dessas relações. Isto se torna mais evidente quando a Etnomatemática é indicada como uma alternativa interessante na Educação Matemática (BRASIL, 2000, p. 173).

O saber matemático e o modo como se dá a relação entre sujeito e conhecimento precisam ser discutidos quando se quer entender como o sujeito aprende e como se pode tornar o ensino escolar significativo. As contribuições de Monteiro e Nacarato (2005) revelam a necessidade de a escola valorizar o sujeito e suas contribuições culturais em situações de aprendizagem, justificando a possibilidade de um conhecimento matemático articulado, em que conhecimentos escolares e cotidianos entrelacem-se e deem margem a construções e interações ricas de significado e sentido aos sujeitos que participam do processo escolar.

Para a diferenciação entre matemática escolar e do cotidiano toma-se como referência as afirmativas de Gómez-Granell (1998), para quem certo tipo 
de conhecimento matemático pode ser desenvolvido fora da escola e à margem da instrução formal, em contextos sociais e práticas culturais. Segundo a autora, trata-se do conhecimento matemático do cotidiano aquele que é desenvolvido no dia-a-dia, a partir de situações informais de aprendizagem. Já o conhecimento matemático escolar, de acordo com ela, refere-se ao domínio da linguagem matemática formal, com intenções predefinidas e objetivos a alcançar. Mais do que discorrer sobre os diferentes modos de conhecer e aprender matemática, é necessária uma breve discussão sobre práticas sociais e culturais que delimitam o aprender e o saber em diferentes contextos.

Lave e Wenger (1991), quando analisam as diferentes formas de aprender em contextos e situações diversas, defendem a aprendizagem como algo inseparável das práticas sociais, sendo que, para estudar e analisar momentos de aprendizagem, é necessário considerar os aspectos sociais envolvidos em tal atividade. Quanto à definição de prática, o referido estudo refere-se à seguinte concepção de Wenger (2001):

O conceito de prática conota fazer algo, mas não simplesmente fazer algo em si mesmo e por si mesmo; é fazer algo em um contexto histórico e social que outorga uma estrutura e um significado ao que fazemos. Neste sentido, a prática é sempre uma prática social (p. 71).

A matemática, de acordo com Abreu (1995), pode ser considerada como prática social, dado que está envolta em ações cognitivas e que a cognição é uma construção individual do sujeito - construção, esta, de caráter social e cultural, pois é mediada por questões sociais e culturais de um dado grupo social de que o sujeito faz parte. Assim, a matemática é uma construção social e, por sua vez, pode ser configurada como prática social.

Miguel (2010) justifica sua escolha em falar de matemática como prática social pelo fato de poder remeter a essa prática um cunho indisciplinar, afinal, a matemática ocorre a partir de diferentes práticas sociais e não apenas por meio de práticas escolares:

Essa característica diferencial complexa, aberta e indisciplinar do construto práticas socioculturais em relação ao caráter abstrato, estático e não situado dos construtos 'saber', 'conhecimento' ou 'conteúdo'- e que o habilita a estabelecer percursos e diálogos indisciplinares de investigação no âmbito da pesquisa científico acadêmica em história (da educação matemática) - foi outra razão que nos induziu a 
tomá-lo como foco da investigação particular aqui referida. [...] esse deslocamento conceitual de conteúdos ou saberes escolares para as práticas escolares sugeriu-nos a ideia de tentarmos esclarecer as características da vida escolar de uma prática sociocultural em função da investigação correlata das características das vidas não escolares dessa mesma prática. (MIGUEL, 2010, p. 7)

Não há como desconsiderar a ordem social da matemática, visto que sua prática se dá em diferentes contextos e situações, estando sempre associada a diferentes práticas sociais (ABREU, 1995). Assim, é possível acatar a existência de diferentes matemáticas relacionadas a práticas sociais e culturais diversas.

Lave e Wenger (1991), quando discutem a aprendizagem da matemática em práticas distintas, não a consideram como um processo de aquisição de saber, mas, sim como um processo de apropriação de práticas sociais:

Nesse sentido, a apropriação não é tanto uma questão de posse, de propriedade, ou mesmo de domínio, individualmente alcançados, mas é essencialmente uma questão de pertencer e participar nas práticas sociais. Nessas práticas, o sujeito - ele próprio um signo, interpretado e interpretante em relação ao outro - existe antes ou independente do outro, do signo, mas se faz, se constitui nas relações significativas (SMOLKA, 2000, p. 37).

Lave (2002) define os meios de estruturação para diferenciar qual matemática está presente em práticas diversas, como nas práticas escolares e nas cotidianas. A autora defende que não se pode entender um processo cognitivo - em particular, matemático - sem considerá-lo como um processo situado, já que este desenvolveu-se num dado contexto social e histórico:

Admitindo-se que a matemática assuma forma universal, capaz de ser transportada para todas as situações e ser executada de modo uniforme, as respostas para essas questões [é válido transportar as descobertas experimentais para atividades desenvolvidas fora do laboratório? [...] Quem deve decidir quais fenômenos cognitivos merecem ser estudados? poderiam ser consideradas simples, e poderiam ser simplesmente aceitas. Não haveria dúvida a respeito da validade da extrapolação de descobertas de 
laboratório para outras situações. Se a prática matemática assume formas específicas de acordo com a situação, isso implica que as propriedades matemáticas formais dos problemas potenciais não são suficientes para verificar quais questões emergirão na prática (LAVE, 2002, p. 69).

As atividades e práticas da matemática, em seus diferentes contextos, dão forma uma à outra; porém, isso não ocorre de modo idêntico. Uma atividade matemática progride e condiciona a forma de outra, mas, ainda de acordo com Lave (2002), elas não se organizam e não possuem efeitos simétricos de organização.

Miguel e Vilela (2008) escolhem referir-se a práticas escolares de mobilização de cultura matemática em vez de aprendizagem da matemática, tendo em vista a preocupação com as diferentes formas de mobilização cultural da disciplina nos contextos diversos em que ocorre a prática da matemática:

[...] as perspectivas de mobilização cultural escolar associadas ao referencial sóciocultural se mostram críticas em relação: a uma concepção de apropriação cultural escolar como derivando-se diretamente de uma impressão sensorial; à linguagem como um sistema de signos ligados a princípios universais de raciocínio; à linguagem como representação do pensamento que, por sua vez, seria a representação do mundo (MIGUEL; VILELA, 2008, p. 108).

Ainda, segundo Miguel e Vilela (2008), quando se trata de mobilizações culturais para estudar práticas matemáticas, a matemática deixa de ser única e fechada a intervenções culturais e sociais:

[...] quando falamos em processos de mobilização de cultura matemática, deixamo-nos de nos referir à matemática como um corpo homogêneo e universal de conhecimentos e passamos a falar em matemáticas no plural. E tais matemáticas passam a ser vistas como aspectos de atividades humanas realizadas com base em um conjunto de práticas sociais, tais como aquelas realizadas pelos matemáticos profissionais, pelos professores de matemática, pelas diferentes comunidades constituídas com base em vínculos profissionais, bem como pelas pessoas em geral em suas atividades cotidianas (MIGUEL; VILELA, 2008, p. 112). 
A busca por maneiras de fornecer significado à matemática escolar por meio de situações contextualizadas - feitas pela simples aplicação de problemas de compra ou de venda, por exemplo - não traz resultados satisfatórios quanto ao modo como o aluno relaciona-se com a matemática escolar. Segundo Vilela (2007), com base na teoria de Lave,

obviamente, os meios de estruturação da matemática envolvida em práticas escolares e da matemática envolvida em práticas não escolares são diferentes, já que as primeiras são realizadas sob os condicionamentos da situação escolar e as não escolares sob os condicionamentos de outras situações (VILELA, 2007, p. 126).

A matemática escolar tem um fim em si mesma, sendo a escola um meio de estruturação específico e restrito. Nesse sentido, Lave (1996) dá ênfase à diferenciação entre práticas em contextos distintos e ao erro de tentar identificálas como práticas matemáticas que mobilizam os mesmos significados aos seus sujeitos:

É importante notar que, para quem cozinha, a resolução de problemas de matemática não constitui um fim em si mesmo; os procedimentos em torno das relações quantitativas que têm lugar na cozinha tomam a forma e o sentido que têm, em função dos impasses, dilemas que servem de motivação às suas práticas; o saber matemático de tipo escolar não limita a estrutura da sua prática quantitativa, nem tão pouco especifica o que é que pode constituir um problema de matemática. [...] Finalmente, devo acrescentar que os tipos de atividades que investigamos não dão para formar um currículo para aprender matemática na escola: a "recolha e transformação das relações de quantidade" não é um algoritmo, ou sequer uma atividade para resolução de problemas, no sentido que lhe dá a escola (LAVE, 1996, p. 120).

O ambiente escolar e as relações que se criam a partir desse contexto são responsáveis pela diferenciação de formas de aprender e conhecer do sujeito que nele se insere. Como afirma Charlot (2001), o saber escolar não substitui o saber criado em outras práticas; ele apenas permite que o sujeito dê outro sentido ao que vê, à vida:

Sua relação com o saber que eles encontraram na escola, e sua relação com a própria escola não se constroem a partir 
do nada, mas a partir de relações com o aprender que eles já construíram. Não se vai à escola para aprender, mas para continuar a aprender. [...] o que se aprende na escola permite dar sentido à vida, mas de outra maneira (CHARLOT, 2001, p. 150).

Lave e Wenger (1991) afirmam que teorias com foco na estrutura das práticas sociais têm uma visão diferenciada das demais teorias, por concentraremse na pessoa e, também, devido à visão impessoal de conhecimento, habilidades e aprendizagem:

Como um aspecto da prática social, a aprendizagem envolve a pessoa como um todo, não apenas uma relação com atividades específicas, mas uma relação com comunidades sociais - implica tornar-se um participante pleno, um membro, um tipo de pessoa. [...] atividades, tarefas, funções e compreensões não existem isoladamente, elas fazem parte de um sistema global de relações em que eles têm um significado (LAVE; WENGER, 1991, p. 33).

Charlot (2001) é autor de estudos que contribuíram para o entendimento e o aprofundamento das relações travadas entre o jovem e o saber em diversos contextos; ele pôde concluir que a relação entre sujeito e saber dá-se de diferentes formas, dependendo da classe social a que os sujeitos pertencem e dos modos como estes interpretam e atribuem significado e sentido ao conhecimento. A ação de um sujeito sobre os outros que convivem no mesmo ambiente de aprendizagem, a reafirmação do saber e a significância do que está sendo aprendido são aspectos importantes para que tal relação entre conhecimento e sujeito ocorra de forma produtiva, levando em consideração o contexto do aluno e quais são suas aspirações relativamente à escola e aos conteúdos escolares. Ainda de acordo com o autor, mais do que fazer com que o aluno se interesse pela escola, é necessário que ele se identifique com ela, podendo reconhecer-se e inteirar-se de modo ativo e dinâmico na construção de novos saberes e na valorização do sujeito social e cultural ativamente presente e responsável pela dinâmica escolar. Afinal,

para compreender a relação dos jovens (da camada popular) com o saber e com a escola, é preciso interessar-se também por suas relações mais gerais com o aprender. Os fracassos, abandonos... que a escola deplora são também efeitos dos conflitos entre formas do aprender (CHARLOT, 2001, p. 151). 
A matemática, mais do que uma disciplina curricular, é objeto social, tal como discutido por Abreu (1995, p. 30): "tanto o conhecimento como as atitudes, e as crenças, são influenciados pelo contexto sócio-cultural das práticas matemáticas". Desse modo, professores e alunos têm representações socioculturais distintas em relação à matemática. Para a autora, sendo a matemática uma representação social, torna-se relevante estudar e analisar sua aprendizagem por meio de uma perspectiva social. Além disso, deve-se considerar a existência de diferentes matemáticas, uma vez que ela está sempre associada a práticas sociais distintas e que, em cada uma dessas práticas, faz-se matemática de acordo com determinadas especificidades.

[...] deixamo-nos de nos referir à matemática como um corpo homogêneo e universal de conhecimentos e passamos a falar em matemáticas no plural. E tais matemáticas passam a ser vistas como aspectos de atividades humanas realizadas com base em um conjunto de práticas sociais, tais como aquelas realizadas pelos matemáticos profissionais, pelos professores de matemática, pelas diferentes comunidades constituídas com base em vínculos profissionais, bem como pelas pessoas em geral em suas atividades cotidianas (MIGUEL; VILELA, 2008, p. 112).

A partir das contribuições dos autores mencionados, é possível notar a importância de o conhecimento matemático estar vinculado a diferentes práticas sociais, com diferentes objetivos e intenções. Tal vinculação possibilita o enriquecimento de momentos de aprendizagem por meio de experiências em práticas sociais distintas, vivenciadas pelos sujeitos escolares, evidenciando que a matemática traz consigo sentidos diversos, uma vez que é ferramenta de diferentes práticas de aprendizagem.

O contexto em que se dá o aprendizado e a relação entre o sujeito que aprende e o saber matemático são responsáveis pelos modos de estruturação e pelas relações criadas com o conhecimento matemático. A matemática, como ferramenta cultural e social, dá suporte ao indivíduo na criação de diferentes interações e na formulação de representações distintas de acordo com o contexto em que é utilizada. Lave (1988) realizou uma pesquisa sobre como se dão as relações entre o sujeito e o conhecimento matemático em contextos extraescolares - no supermercado, por exemplo. A autora concluiu que uma mesma atividade, em situações diferentes, gera a própria configuração de outras atividades e lhes fornece meios de estruturação, pois, segundo ela, 
uma teoria da prática considera o aprendizado, o pensamento e o conhecimento como processos histórica e culturalmente específicos, socialmente constituídos e politicamente ajustados, e argumenta que eles estruturam claramente o mundo social, assim como são estruturados por ele (LAVE, 1988, p. 123, tradução nossa).

Discutindo a importância da aprendizagem situada, e considerando o contexto e as situações em que se desenvolve todo o processo de aprender, Lave e Wenger (1991) tomam diferentes comunidades como referência para analisar e discutir a denominada comunidade de prática; em suas palavras, "uma comunidade de prática é uma condição intrínseca para a existência de conhecimento" (LAVE; WENGER, 1991, p.98, tradução nossa). Como afirmam Miguel e Vilela (2008, p. 115), a expressão comunidades de prática foi desenvolvida por Wenger para "designar um sistema de atividades realizadas por um grupo de pessoas que compartilham compreensões sobre aquilo que fazem e sobre os significados dessas ações no âmbito da comunidade". Devido aos modos de conhecer e aprender desenvolvidos em tais comunidades de prática, Lave e Wenger (1991, p. 93, tradução nossa) defendem uma modificação nos currículos e na postura didática da escola, afinal, "um currículo de aprendizagem se desenvolve em oportunidades para o engajamento na prática. Não pode ser especificado por um conjunto de ordens para a prática adequada". Os autores justificam a relevância de sua teoria pelo fato de que toda atividade de aprendizagem ocorre em situações distintas, não existindo, segundo essa perspectiva, aprendizagem que não esteja situada; enfatizam, também, a importância do ambiente em que se dá o processo de aprendizagem. Os alunos trazem consigo vastos conhecimentos matemáticos já adquiridos em diferentes situações - de trabalho, cotidianas, entre outras -, o que justifica as afirmações de Lave e Wenger (1991) sobre a necessidade do resgate de saberes envolvidos em situações e contextos únicos, dando sentido e significado ao conhecimento a ser adquirido. Porém, não se pode esperar que a matemática praticada em sala de aula seja similar à sua prática em outros contextos, com mesmos valores e representações aos seus sujeitos, pois:

[...] praticamente nenhum problema em uma loja ou na cozinha foi resolvido sob forma do algoritmo escolar. As regras de transformação (que eliminam aproximações algorítmicas para frações e decimais) não são transferidas, como também não o são as notações de posições fixas (já 
que lápis e papel não são utilizados), os cálculos, a trigonometria, álgebra etc. De fato, a questão devia ser: existe algo que é transferido? (LAVE, 2002, p. 66).

Pode-se concluir, assim, que os objetivos do processo de ensino e aprendizagem de matemática na escola devem ser claros, com o intuito de auxiliar no desenvolvimento do raciocínio lógico e abstrato do aluno. Assim, a matemática não deve ser desvinculada de sentido, mas estar de acordo com cada atividade a que ela se torna útil e com as necessidades de cada sujeito que a utiliza como ferramenta social.

A escola ainda trata de um conhecimento descontextualizado, com situações de ensino muito específicas e pouco significativas para os alunos. No entanto, como afirmam Lave e Wenger (1991), uma aprendizagem escolar situada requer uma visão de multicamadas, em que conhecimento e aprendizagem sejam partes de uma prática social, de um grande projeto em si.

O ensino de matemática na escola não oferece referências ou mesmo valores aos sujeitos desse processo de aprendizagem:

O sistema escolar hoje existente está alicerçado nos interesses de uma determinada classe dominante e organizase a partir de discursos, valores e princípios cultivados e presentes no cotidiano dessa classe, excluindo do processo escolar não apenas os saberes e fazeres que diferem do padrão constituído, mas, especialmente as pessoas que produzem esses saberes (MONTEIRO; GONÇALVES; SANTOS, 2007, p. 50).

Monteiro, Gonçalves e Santos (2007) defendem a valorização de práticas e saberes excluídos do contexto escolar, o que possibilitaria aos sujeitos sua identificação e seu envolvimento com os saberes escolares a serem construídos. Segundo os autores, o saber escolar limita-se aos interesses de uma classe e não dá espaço a articulação de novos saberes aos sujeitos que fazem parte de classes sociais e culturais distintas. A pesquisa feita por Pompeu (2011) revela a padronização do ensino de matemática através do que deva ser necessário aos alunos, sem levar em conta suas contribuições pessoais e suas experiências com matemática fora do ambiente escolar. Ainda que os documentos oficiais defendam a contextualização do saber, essa contextualização é feita a partir de padrões impostos e não de acordo com a necessidade de cada instituição escolar. Quando um grupo de alunos discute sobre a evasão escolar através da construção 
de gráficos (POMPEU, 2011), a fala do aluno A1 pontua:

a parte mais difícil foi saber o que era um gráfico, como usar e construir um gráfico. Minha filha está na $8^{\text {a }}$ série e já aprendeu isso, então pedi ajuda a ela. Quando procuramos um gráfico no jornal, ninguém conseguiu entender muito bem, por isso resolvemos fazer um mais simples. Já fazia um tempo que tínhamos percebido que a turma estava menor, então com as chamadas dos meses anteriores conseguimos ver que diminuiu mais de 10 alunos. Eramos em agosto 45 alunos, em setembro 4 alunos não estavam mais vindo e agora já são 7 a mais. Então fica assim:

Agosto - 45 alunos Setembro - 41 alunos Outubro - 34 alunos Fizemos então o gráfico com isso, usando os meses e o número de alunos em cada mês (p. 74).

É possível instigar, a partir desse momento, novas discussões e interações entre a ferramenta matemática e suas possibilidades de utilização, porém essas novas discussões não ocorreram. A escola segue padrões que não dão espaço aos alunos que fazem parte dela, sujeitos que trazem consigo saberes relevantes, que precisam ser articulados ao saber escolar para dar sentido ao que se configura como escola para esses sujeitos.

No que concerne às práticas sociais e às contribuições de Lave, como afirmam Miguel e Vilela (2008, p. 116), "ainda que os estudos realizados por Lave incidam sobre práticas não-escolares que mobilizam cultura matemática, eles nos parecem de grande valia para se entender também as práticas tipicamente escolares".

A análise e a reflexão sobre as diferentes práticas envolvendo a matemática são essenciais quando se trata de entender a relação e os modos de interação do sujeito escolar com o saber matemático.

[...] falar em matemática escolar, em vez de simplesmente matemática, ou em educação matemática escolar, em vez de simplesmente educação matemática ou, ainda, em práticas escolares mobilizadoras de cultura matemática, em vez de simplesmente práticas mobilizadoras de cultura matemática, começa a se tornar um fator imprescindível para a identificação e interpretação da diversidade e da identidade culturais e, conseqüentemente, para a análise de práticas culturais situadas (MIGUEL; VILELA, 2008, p. 117-118).

Muitos indivíduos fracassam quando se deparam com o conhecimento 
matemático escolar e desestimulam-se por não encontrarem sentido no estudo de tais formalizações trabalhadas na escola. Quando o sujeito atribui significado e valor ao conhecimento matemático, ele consegue estruturar e criar modos próprios de pensar, a partir do que é ensinado.

As possíveis relações do sujeito com o conhecimento ocorrem de diversas formas, porém, há a necessidade de tornar tais relações significativas para o sujeito em questão, uma vez que a articulação entre conhecimentos adquiridos em contextos distintos torna possível a análise sobre como o conhecimento anterior ao processo escolar do aluno, bem como sua formação construída cultural e socialmente fora da escola, agem de forma auxiliar e complementar na aprendizagem e na construção de saberes escolares.

Pompeu (2011), em sua dissertação de mestrado, analisou como se dá a relação dos alunos com o conhecimento matemático num ambiente escolar de EJA (Educação de Jovens e Adultos). Por meio de entrevistas e observações coletadas durante um semestre, foi possível perceber que, apesar de os alunos não serem estimulados a relacionar a matemática escolar com a extraescolar, eles conseguem articular conhecimentos abstratos tratados em sala de aula com situações vivenciadas fora da escola, como no caso do aluno A5, trabalhador em obras, que relatou sua experiência com o calculo de áreas:

A5 afirmou que, uma vez sabendo as medidas da sala, é possível saber quantos pisos caberão nela. Ele justificou: "se uma sala tem 3 metros de profundidade por 5 de largura, e se o piso tem 1 metro por 1 metro, a gente sabe que cabe 3 por 5 . Mas se não for de 1 metro por 1 metro é só multiplicar as medidas e depois dividir pelo tamanho do piso que a gente sabe quantos pisos cabem ali" (POMPEU, 2011, p. 76).

O aluno precisa sentir-se presente na construção dos saberes e das ferramentas matemáticas a serem apreendidas e, de acordo com Bishop (1999), necessita que a aprendizagem se faça de modo reflexivo e contextualizado, fundamentada em atividades e anseios específicos para cada comunidade escolar. Assim, cada região ou cultura pode fornecer especificidades ao ensino de matemática, enriquecendo o processo de aprendizagem. Como justifica Bishop (1999, p. 27, tradução nossa), “o fato de que as verdades matemáticas sejam válidas em toda parte e para qualquer pessoa não tem razão nenhuma para dizer que a educação matemática deva ser igual em toda parte e para todo o mundo". A aprendizagem matemática impessoal despersonaliza o processo de ensino, 
ignorando conexões e significações pessoais. Uma vez que "contemplamos a educação matemática como um processo social, o indivíduo negocia, integra e compreende as diferentes mensagens relacionando-as com valores" (BISHOP, 1999, p. 33, tradução nossa).

Os modos de apropriação e de relação entre o sujeito e a matemática, seja ela escolar ou não, tornam-se importantes ferramentas no processo de estudo e análise da matemática e na observação de sua relação com o sujeito que aprende, tal como justifica Mantencio (2005) e Valverde (2006) em sua pesquisa sobre as relações entre a linguagem materna e a linguagem matemática e sobre como ambas contribuem para seus respectivos desenvolvimento e aprimoramento. Do mesmo modo Matencio (2005) discute sobre a matemática e o desenvolvimento do sujeito:

[...] a Matemática pode auxiliar os alunos a entenderem a passagem de uma linguagem natural para uma linguagem artificial, linguagem esta que permite a modelização de operações realizadas com objetos - operações essencialmente de abstração -, portanto, linguagem que faz com que equações sirvam tanto para representar a soma dos ingredientes de uma receita simples que se pretende duplicar, modelando um raciocínio que poderia ser seguido por qualquer falante em seu cotidiano, quanto para representar as razões da alta dos juros, modelando saberes científicos que emergem no âmbito de embates sociais e políticos (MATENCIO, 2005, p. 22).

Assim sendo, modos diversos de relacionar-se com o conhecimento são fundamentais para entender como o sujeito concede sentido e significado àquilo que aprende. A relação que se dá entre sujeito e conhecimento, para além do simples processo de receber uma nova informação, requer o entendimento do modo de conhecer de cada sujeito, do seu desejo de aprender e dos significados atribuídos ao novo saber. O sujeito relaciona-se com o conhecimento matemático por intermédio de diferentes experiências, escolares ou não, e atribui a cada nova experiência um significado que o torna um sujeito único, capaz de ressignificar o que lhe foi ensinado e de modificar o processo de aprendizagem com suas experiências e contribuições de vida. Com a aula de matemática não pode ser diferente, uma vez que as diversas matemáticas, significadas em diferentes práticas sociais, configuram-se de um modo único para cada sujeito, tornando-o capaz de analisar e relacionar suas experiências de acordo com o desejo de aprender e conhecer. 


\section{Considerações finais}

São complexas as discussões sobre como a escola deve portar-se para fornecer significado e sentido àquilo que é aprendido. Porém, como assevera Lave (1988), a escola não atribuirá ao conhecimento os mesmos significados e objetivos que se têm em um momento de aprendizagem não escolar (como um momento de compra, ou de troca de saberes em comunidades de aprendizagem), mas é possível que ela faça uso de tais vivências para dar sentido e tornar as relações entre sujeito e conhecimento ainda mais entrelaçadas. Não é possível lidar com a matemática sem considerar os processos e os meios em que ela se desenvolve; além disso, matemática escolar e não escolar complementam-se na busca de significados ao que é aprendido pelos alunos. O desejo de aprender e saber apresenta-se de diferentes formas e em momentos diversos da aprendizagem, sendo relevante que a escola instigue o aluno a aprender e a ressignificar o que aprendeu, de forma a sentir-se agente fundamental no processo de ensino e aprendizagem escolar. As contribuições de Charlot (2001) e seus estudos, acerca da relação do jovem com o saber, remete-nos a novas possibilidades de perceber o sujeito escolar e de fazer do ambiente escolar um espaço de desejos e novas expectativas.

O ensino da matemática é motivo de graves embates quanto aos modos de concebê-lo. O desejo de aprender, apesar do evidente esforço de seus sujeitos, precisa fazer parte da rotina escolar diária dos alunos, tornando-os membros da comunidade escolar. Fazer parte efetiva da escola e poder contribuir com o grupo é identificar-se e partilhar saberes. Para ser membro da escola, sendo esta uma comunidade de prática, é necessária "a participação num sistema de atividade sobre o qual os participantes partilham compreensões sobre aquilo que fazem e o que isso significa nas suas vidas e comunidades" (LAVE; WENGER, 1991, p. 98, tradução nossa). O ensino de matemática escolar, mais do que elevar a relevância do conhecimento acadêmico ou do ensino da disciplina ligada ao cotidiano, deve estar emaranhado pelas diferentes práticas matemáticas.

[...] ao invés de se ver continuidade entre uma matemática e outra, decorrente da compreensão de que uma deveria ser parte ou germe de outra, seria preferível vê-las como conjuntos idiossincráticos de atividades que, embora não incomensuráveis, mantêm entre si apenas "semelhanças de família" e, nesse sentido, conhecer uma matemática depende de conhecer qual é o jogo que a envolve (VILELA, 2007, p. 229-230). 
Desse modo, a escola como comunidade de prática, e com seus membros partilhando de um bem comum, precisa estar imersa de desejos de saber. Segundo Charlot (2001, p. 49), contudo, "a relação com a escola pode envolver representações da escola, mas, também, do futuro, da família, presente e futura, do trabalho e do desemprego na sociedade de amanhã, das tecnologias modernas, etc.". O desafio da escola é fazer com que esse desejo emerja nas práticas escolares: "a questão é compreender, portanto, como se passa do desejo de saber (da busca do gozo) à vontade de saber, ao desejo de aprender, e, além disso, ao desejo de aprender e saber isso ou aquilo".

É relevante destacar o papel da matemática como ferramenta de utilidade em atividades diárias, tal como foi afirmado pelos alunos entrevistados por Pompeu (2011); no entanto, a matemática tem sua função formativa no desenvolvimento de estruturas do modo de pensar e do raciocínio lógico e dedutivo. Como afirma Bishop (1988),

a matemática, além de ser um certo tipo de tecnologia simbólica, é também condutora, e produto, de certos valores. Se somente procurarmos entender a matemática como uma tecnologia simbólica particular, somente entenderemos uma parte - talvez, na verdade, para a educação e para o nosso futuro, a parte menos importante (p. 208, tradução nossa).

Este estudo reitera a necessidade de uma interação entre os diversos conhecimentos adquiridos em diferentes contextos. Mais do que discutir sobre contextualização do saber matemático, este artigo articula novos modos de ver e perceber a matemática e a relação desse saber com os sujeitos que aprendem. $\mathrm{O}$ contexto em que ocorre a troca ou aquisição do saber influencia nos modos de relação do sujeito com o conhecimento. Assim, não é possível fazer da sala de aula um momento de compra dotado dos mesmos objetivos de quando o sujeito vai ao supermercado, pois cada contexto tem um foco de problema diferenciado. Porém, é possível fazer com que as ferramentas adquiridas por meio de atividades de compra, por exemplo, auxiliem na mobilização de saberes já conhecidos pelos alunos, dando margem à ampliação e à formalização de novos saberes matemáticos. Os alunos participantes das entrevistas mostraram que, além de força de vontade, tinham a curiosidade e o desejo pelo saber, mas não se identificavam ou não se reconheciam como sujeitos relevantes no processo escolar, ignorando a validade e a importância das contribuições oriundas de suas experiências de vida. 
Tratar a matemática como prática social requer, para seu estudo e análise, contribuições culturais e sociais daqueles que relacionam e interagem por intermédio desse saber. Cabe à escola ampliar as relações dos sujeitos com o conhecimento matemático de forma mais complexa e sistemática, porém com novas possibilidades de pensamento e desenvolvimento do sujeito.

O objetivo deste artigo foi discutir sobre o modo que se dá a relação do sujeito com o conhecimento matemático no interior do ambiente escolar, a partir de teorias de aprendizagem situada. A partir das referências mencionadas e das experiências de pesquisa vivenciadas pela autora, é possível destacar que a escola ainda inibe as relações entre os sujeitos que aprendem e o conhecimento, embora tais relações sejam necessárias para que ocorra uma evolução da escola e de suas contribuições para a sociedade. Desse modo, não se pode falar em processo de ensino e aprendizagem desvinculando o sujeito de suas experiências extraescolares, ou mesmo em conhecimento escolar sem que se leve em consideração os diferentes modos de aprender e de conhecer decorrentes das experiências de vida de cada sujeito.

O aluno, entendido como sujeito social, leva contribuições únicas e enriquecedoras para os diferentes contextos de que participa, contribuições que aludem à relevância de cada sujeito no processo de aprender. A escola necessita trazer para dentro de seu contexto as contribuições desses sujeitos, bem como evidenciar, em seus momentos de interação, o desejo de cada um pelo conhecimento, o desejo de interagir com o outro e de modificar o outro por meio de suas manifestações de conhecer e saber. Cada sujeito precisa sentir-se parte da escola para que possa conceder significado a ela e aos conhecimentos construídos a partir do contexto escolar.

\section{Referências}

ABREU, G. A teoria das representações sociais e a cognição matemática. Quadrante, Lisboa, v. 4, n. 1, p. 25-41, 1995.

BISHOP, A. J. Mathematical enculturation: a cultural perspective on mathematics education. Dordrecht: Kluwer Academic Publishers, 1988.

BISHOP, A. J. Enculturación matemática: la educación matemática desde una perspectiva cultural. Barcelona: Ed. Paidós, 1999. 
BRASIL. Ministério da Educação. Secretaria de Educação Média e Tecnológica. Parâmetros Curriculares Nacionais para o Ensino Médio - Bases Legais. Brasília: MEC/SEMTEC, 2000.

CHARLOT, B. Os jovens e o saber: perspectivas mundiais. Porto Alegre: Ed. Artmed, 2001.

DEWEY, J. Experiência e natureza. São Paulo: Abril Cultural, 1974. (Coleção Os pensadores).

GÓMEZ-GRANELL, C. Rumo a uma epistemologia do conhecimento escolar: o caso da educação matemática. In: RODRIGO, M. J.; ARNAY, J. (Orgs.). Domínios do conhecimento, prática educativa e formação de professores. São Paulo: Ática, 1998. p. $15-41$.

LAVE, J. Cognition in practice: mind, mathematics and culture in everyday life. Cambridge: Cambridge University Press, 1988.

LAVE, J. A selvageria da mente domesticada. Revista crítica de ciências sociais. Coimbra, n. 46, p. 109-134, 1996.

LAVE, J. Do lado de fora do supermercado. In: FERREIRA, M. K. (Org.). Idéias matemáticas de povos culturalmente distintos. São Paulo: Global, 2002. p. 65-98.

LAVE, J.; WENGER, E. Situated learning: legitimate peripheral participation. Cambridge: Cambridge University Press, 1991.

MATENCIO, M. L. M. A leitura na formação e atuação do professor de educação básica. In: MARI, H.; WALTY, I.; VERSIANI, Z. (Orgs.). Ensaios sobre leitura. Belo Horizonte: PUC Minas, 2005. p. 15-32.

MIGUEL, A. Percursos indisciplinares na atividade de pesquisa em história (da educação matemática): entre jogos discursivos como práticas e práticas como jogos discursivos. Bolema - Boletim de Educação Matemática, Rio Claro, v. 23, n. 35A, p. 157, abr. 2010.

MIGUEL, A.; VILELA, D. S. Práticas escolares de mobilização de cultura matemática. Cadernos CEDES, São Paulo, v. 28, n. 74, p. 97-120, abr. 2008.

MONTEIRO, A.; GONÇALVES, E.; SANTOS, J. A. Etnomatemática e prática social: considerações curriculares. In: MENDES, J. R.; GRANDO, R. C. (Orgs.). Múltiplos olhares: matemática e produção de conhecimento. São Paulo: Musa Editora, 2007. p. 29-63. 
MONTEIRO, A.; NACARATO, A.M. As relações entre saberes cotidiano e escolar presentes nos Parâmetros Curriculares Nacionais de Matemática. Pro-Posições, Campinas, v. 16, n. 3, p. 165-179, set./dez. 2005.

POMPEU, C. C. A experiência escolar de jovens e adultos e sua relação com a matemática. 2011. 125f. Dissertação (Mestrado em Educação) - Universidade de São Paulo, São Paulo, 2011.

SMOLKA, A. L. B. O impróprio e o impertinente na apropriação das práticas sociais. Caderno Cedes, São Paulo, v. 20, n. 50, p. 26-40, abr. 2000.

VALVERDE, R. M. S. de M. Interações em aula de matemática para jovens e adultos. 2006. 186f. Dissertação (Mestrado em Educação) - Universidade Estadual de Campinas, Campinas, 2006.

VILELA, D. S. Matemáticas nos usos e jogos de linguagem: ampliando concepções na Educação Matemática. 2007. 247f. Tese (Doutorado em Educação) - Universidade de Campinas, Campinas, 2007.

WENGER, E. Comunidades de práctica: aprendizaje, significado e identidad. Barcelona: Paidós, 2001.

Submetido em Fevereiro de 2012. Aprovado em Abril de 2012. 